\title{
As políticas públicas e os projetos de assentamento ${ }^{1}$
}

\author{
Francisco José Batista de Albuquerque \\ Jorge Artur Peçanha de Miranda Coelho \\ Tatiana Cristina Vasconcelos \\ Universidade Federal da Paraíba
}

\begin{abstract}
Resumo
Para analisar a relação existente entre as políticas públicas e os projetos de assentamento para a reforma agrária, investigaram-se as crenças e as expectativas de assentados, bem como de técnicos do INCRA da Paraíba, sobre as políticas públicas direcionadas para o desenvolvimento rural, especificamente para os projetos de assentamento. Participaram deste estudo 4 agentes de desenvolvimento rural do INCRA e 52 assentados, compondo um total de 56 participantes. Os resultados indicaram que assentados e técnicos apresentaram crenças de que a organização do assentamento em forma de parcela é mais adequada para o seu bom funcionamento do que em forma de agrovila. Os assentados opinaram que mantêm pouca relação com os pequenos produtores seus vizinhos, descrevendo-os como preconceituosos. Os dois grupos de participantes crêem que o PRONAF traz poucos benefícios, maior dificuldade na forma de pagamento, morosidade na aprovação dos projetos e na liberação do fomento, em comparação com o programa de crédito anterior, o PROCERA. Assentados e técnicos convergem no sentido de atribuir um papel de assistência técnica aos agentes de desenvolvimento rural do INCRA, no que diz respeito à organização das atividades agropecuárias, implementação de associação e cooperativa no assentamento, bem como na sua estrutura social. Não obstante, os participantes apresentam a crença de que o Estado deve assumir o papel de gerenciador das condições necessárias para o bom funcionamento do assentamento.
\end{abstract}

Palavras-chave: reforma agrária; políticas públicas; assentamentos.

\begin{abstract}
Public policies and settlement projects. To analyze the existing relationship between public policies and settlement projects for agricultural reform, we investigated the beliefs and the expectations of settlers as well as those of the Paraíba INCRA's technicians, in terms of public policies towards rural development, as regards settlement projects. The study group was made out of 4 INCRA rural development agents and 52 settlers, thus producing a sample of 56 members. The results showed that settlers and technicians believe that the parcel shape of the settlement organization runs better than the agro-villa format. Settlers say that they maintain a poor relationship with their neighboring small growers, while describing them as prejudiced people. The two groups of partakers believe that PRONAF brings few benefits, a higher difficulty in the way of payment and slowness in the approval of the projects and the liberation of resources, if compared to PROCERA, the previous program of credit. Settlers and technicians agree on attributing the role of technical assistance to the INCRA rural development agents, as regards the organization of agricultural and cattle raising activities, implementation of the association and cooperative settlement, and also in terms of social structure. However, partakers believe that the State should play such a role as to manage the required conditions towards a better running of the settlement.
\end{abstract}

Key-words: agricultural reform; public policies; settlements.

\section{A questão agrária e as políticas públicas}

A s singularidades existentes no ambiente rural têm propiciado debates e pesquisas no Brasil (ver Carvalho, 1998; Buanain, Silveira, \& Teófilo, 1998; Carmo, 1999), especificamente no que tange ao processo de reforma agrária e às políticas públicas implementadas recentemente no ambiente rural. Os projetos de assentamento são pontos impor- tantes desse processo, tendo por finalidade maior integrar os assentados à sua comunidade circunvizinha, fazendo com que produzam para a sua subsistência e comercialização.

As políticas públicas envolvem questões de valores e de recursos disponíveis, por isto, desenvolver uma ou outra política depende do que se considera que é desejado socialmente. Portanto, são os critérios seguidos no momento de se 
estabelecer as prioridades dos recursos disponíveis que direcionam a distribuição e transferência de renda de um agente social para outro (Rodríguez \& Ardid, 1996).

A questão agrária sempre esteve presente nos rumos do processo de desenvolvimento do Brasil (Carmo, 1999). Entretanto, ocorreu de diversas maneiras, passando por fases distintas. Em um primeiro momento, houve um forte predomínio do setor primário, que durou até o início dos anos sessenta, quando, de modo similar ao que ocorria em outras partes do mundo, foi sendo introduzido com mais força o modelo de desenvolvimento de substituição da importação de produtos manufaturados por uma industrialização crescente, transferindo recursos da agricultura para outras áreas da economia. Em seguida, a partir da década de 60, os governos militares promoveram a modernização do latifúndio, em detrimento do incentivo aos pequenos produtores, ocasionando a migração de milhares de pessoas para os grandes centros cosmopolitas (Teixeira \& Martin, 1998). Como conseqüência desse modelo concentrador de renda, diferentemente de outros países europeus ou norte-americanos, em que o pequeno agricultor foi poupado, chegou-se a uma situação de grande disparidade econômica e de qualidade de vida da população brasileira, uma vez que se verificou uma migração elevada, em um curto espaço de tempo, para poucas cidades, gerando bolsões de concentrações humanas em condições de vida muito precárias.

Nos últimos anos, percebe-se que governo e sociedade constatam a falha desse modelo excludente, coincidindo sobre a necessidade de acelerar e expandir o programa de reforma agrária e as intervenções fundiárias, através de projetos de assentamentos do INCRA (Instituto Nacional de Colonização e Reforma Agrária), que adquiriram um papel de grande destaque entre as políticas públicas atualmente em vigor, sem, contudo, se chegar a um consenso. A simples expansão do programa de reforma agrária foi suficiente para colocar em debate sua eficácia e sustentabilidade, gerando novas políticas de reordenamento fundiário (Buanain, Silveira, \& Teófilo, 1998). Surgiu então, no ano de 1997, o PRONAF (Programa Nacional de Fortalecimento da Agricultura Familiar), que elegeu a agricultura familiar como prática orientadora do desenvolvimento rural. Mesmo levando em consideração todos os impasses da ação pública, não deixa de ser um indicativo de mudança nesse âmbito, num país que há muito vem privilegiando a agricultura patronal (Carneiro, 1998).

Neste conjunto de políticas foi mantida a velha idéia de que o interior é unicamente formado por padrões agrários. Por conta disto, deixou-se de investir e de incentivar outras formas de desenvolvimento rural que não estivessem vinculadas diretamente ao agro. Entretanto, essa já não é a forma privilegiada de produção econômica que se encontra na zona rural. Como afirmam Albuquerque, Lobo e Raymundo (1999), faz-se necessário diferenciar o agrário do rural, sendo este último muito mais global e envolvendo muitos outros fatores. O mundo rural deixou de ter, como única ou principal fonte de renda, a produção agrária. Este fato, que se verificou nos países mais desenvolvidos, chega agora com muita força em nosso país. As pequenas indústrias, o comércio, os serviços e as aposentadorias constituem hoje os principais vetores de recursos para os pequenos municípios brasileiros.

As contradições no ambiente agrário, entre agricultores com grandes extensões de terras, outros com pouca terra e a maioria sem nenhuma, teve, no início da década de 60 , um escoadouro social com as Ligas Camponesas no Nordeste e os movimentos sociais de luta pela reforma agrária, que foram aniquilados pelo regime militar a partir de 1964, impedindo o desenvolvimento de uma agricultura familiar como atividade econômica especializada, intensiva e permanente. Não obstante, no âmbito do discurso, se priorizou a agricultura familiar, mas ainda hoje esta se mantém afastada do desenvolvimento tecnológico e com produção insuficiente para se inserir no mercado agrícola. Portanto, apenas implementar projetos de assentamentos e favorecer e incentivar a agricultura familiar, sem proporcionar o desenvolvimento e mecanização da produção, ocasiona despesas homéricas e faz com que os agricultores familiares continuem à margem do desenvolvimento e mercado, e sempre necessitando da assistência do Estado. Atualmente, é o MST (Movimento Nacional dos Trabalhadores Rurais Sem Terra) que predominantemente congrega as forças sociais que encarnam essas contradições, buscando a reforma agrária como solução para esse desequilíbrio. Sendo o principal contraponto às políticas públicas voltadas para a agricultura, sua face mais visível é a organização de invasões de terras, com o fito de forçar a sua desapropriação para fins de reforma agrária.

\section{Os assentamentos}

Os assentamentos estão apoiados por uma política de crédito própria, através do INCRA, que financia a implantação dos lotes, com recursos para a construção da moradia, da manutenção da família no primeiro ano, além de financiar o custeio da produção e disponibilizar crédito para investimento, com prazos e carências. Além disso, nos últimos anos, foi implementado o Projeto Lumiar, que deixou de funcionar ao final do ano de 1999. Esse projeto objetivou fornecer assistência técnica aos assentados, pois esta era uma das suas reivindicações históricas. Tinha por finalidade maior: o desenvolvimento das famílias assentadas; a consolidação dos projetos de assentamento e sua inserção no Município ou região como unidade de produção competitiva, geradora de renda e emprego; suprir a necessidade de assistência técnica e a capacitação das famílias assentadas, no que diz respeito à implantação e desenvolvimento de culturas e pastagens, armazenamento e comercialização, criação de animais e introduzir novas tecnologias e ações de estímulo à organização dos assentados (Ministério Extraordinário de Política Fundiária, 2001).

A qualidade de vida nesses assentamentos, em que pese a sua precariedade, é percebida pelos assentados como tendo melhorado em relação à que usufruíam anteriormente. Pode-se supor que o patamar anterior de qualidade de vida era muito baixo; era o patamar em que se encontrava e em que ainda hoje se encontra a maioria dos brasileiros pobres que habitam o ambiente agrário. A própria constituição do assentamento apresenta-se como uma estratégia de inserção social 
por parte dessa população excluída. Assim, mesmo com todas as dificuldades, o assentamento é uma alternativa consistente (Leite, 1998). Além disso, ressalte-se a não preocupação com as terras desapropriadas, que geralmente são terras consideradas improdutivas.

Postula-se que estas terras são improdutivas devido a dois fatores: (1) o solo não apresenta fertilidade suficiente para que se possa investir na produção agropecuária e (2) localizam-se à grande distância em relação aos centros comerciais.

Bittencourt, Castilho, Bianchini e Silva (1999), realizaram um estudo sobre os principais fatores que afetam o desenvolvimento dos assentamentos de reforma agrária no Brasil. Concluíram que a qualidade físico-química dos solos, a disponibilidade de água, a freqüência das chuvas e o relevo têm sido aspectos importantes para determinar o nível de desenvolvimento dos assentamentos. Além disso, tais aspectos podem ser considerados como pré-condições para o êxito dos projetos de assentamento. Sendo assim, o quadro natural é um fator central que pode não só determinar a diferença entre os assentamentos com maior ou menor nível de desenvolvimento, mas também, impossibilitar o próprio desenvolvimento produtivo.

Com relação ao segundo postulado, que leva em consideração o distanciamento dos projetos de assentamento dos centros comerciais, as vias de acesso, quando existem, são de extrema precariedade. Tal aspecto foi sublinhado por Bittencourt e colaboradores (1999), que evidenciaram que os projetos de assentamentos "localizados em entorno com produção agropecuária mais dinâmica - que contam com a presença de mercados específicos interligados com agroindústrias - tendem a se beneficiar desse entorno, conseguindo inserir a produção dos assentados nessas cadeias produtivas (p. 22)”. Ou seja, a proximidade do mercado consumidor e o seu acesso são fatores relevantes para o êxito do assentamento.

Sendo assim, a desapropriação de terra tem se tornado um negócio rentável para os latifundiários, que vêem valorizadas, a peso de ouro, suas terras, tidas, por definição, como improdutivas. Este tipo de constatação acaba por solapar, nas bases, os esforços do órgão governamental responsável pelo desenvolvimento rural (INCRA) e do movimento dos Trabalhadores Rurais Sem Terra (MST) em implementar uma reforma agrária eficaz. E são os assentados, em última instância, os principais envolvidos, sendo muitas vezes a eles atribuída a responsabilidade do resultado final de todo esse processo, o êxito ou fracasso de toda essa política fundiária.

Contudo, subjacentes aos aspectos supracitados para o sucesso ou fracasso dos projetos de assentamento, estão os aspectos psicossociais, quase sempre deixados de lado pelos investigadores, pois, no Brasil, existe uma escassez de estudos neste âmbito, sob a luz da Psicologia Social.

\section{Crenças e expectativas}

Com efeito, faz-se necessário investigar os aspectos psicossociais dos assentados e agentes de desenvolvimen- to rural, tais como as crenças e expectativas com relação às políticas públicas voltadas para os projetos de assentamento, como uma tentativa de suprir as deficiências acima apontadas.

Crenças são as informações que uma pessoa dispõe acerca de um objeto, sempre associadas a uma probabilidade de veracidade como diz Rokeach (1981); “uma crença é uma proposição simples, consciente ou inconsciente, inferida do que uma pessoa diz ou faz, capaz de ser precedida pela frase 'eu acredito que...'” (p. 92). Por sua vez, expectativas são definidas como sendo as crenças que os indivíduos dispõem acerca de um objeto, pessoa ou situação, mais especificamente voltadas para o futuro (Rokeach, 1981).

O levantamento das crenças e expectativas dos assentados e agentes de desenvolvimento rural, sobre temas como a atuação do INCRA junto aos projetos de assentamento, o crédito rural, as expectativas quanto ao futuro do assentamento e a relação entre assentados e comunidade circunvizinha, servirá como base para que se possam propor metodologias e ações que favoreçam o objetivo final do assentamento, que é o de sua completa integração com a comunidade circunvizinha, visando a produção para a subsistência e a comercialização. Este objetivo, aparentemente óbvio, não é consistentemente percebido nem por parte dos órgãos responsáveis pela reforma agrária, nem pelos próprios assentados.

O objetivo do presente trabalho é descrever as crenças e as expectativas de pequenos produtores paraibanos, oriundos do projeto de assentamento da reforma agrária (assentados), bem como de agentes de desenvolvimento envolvidos no processo através do INCRA, sobre políticas públicas direcionadas para o desenvolvimento rural, especificamente para os projetos de assentamento.

\section{Método}

\section{Participantes}

Participaram deste estudo 04 agentes de desenvolvimento rural do INCRA/PB e 52 assentados do Assentamento Dona Helena, situado no Município de Cruz do Espírito Santo, $\mathrm{PB}$, compondo um total de 56 participantes.

\section{Instrumento}

Foi utilizado um roteiro de entrevista, composto de 15 questões. Os agentes de desenvolvimento rural responderam a 8 questões, do tipo "qual o papel dos agentes de desenvolvimento rural, frente ao trabalho realizado nos projetos de assentamento?” e "qual a sua opinião sobre a organização dos assentados?”. Os assentados responderam a 7 questões, do tipo "qual a sua opinião sobre a organização deste assentamento?” e “o que você pensa com relação ao trabalho realizado pelos agentes de desenvolvimento agrário?”. As questões foram formuladas de modo que possibilitassem a manifestação dos participantes sobre os seguintes temas: (1) atuação do INCRA na implementação e forma de organização do assentamento; (2) crédito rural (PRONAF); 
(3) papel dos agentes de desenvolvimento rural do INCRA; (4) futuro do assentamento; e (5) relação entre os assentados e as comunidades circunvizinhas.

\section{Procedimento}

Utilizou-se um procedimento padrão para aplicação da técnica de grupo focal, tendo os pesquisadores entrevistado os assentados de acordo com o seu próprio sexo: os pesquisadores entrevistaram os participantes do sexo masculino, e as pesquisadoras entrevistaram as participantes do sexo feminino. Devido à dificuldade de reunir os participantes em pequenos grupos, fez-se necessário utilizar, como técnica complementar de coleta de dados, além da técnica de grupos focais, a entrevista individual.

Os grupos focais e entrevistas foram realizados na sala ou terraço da casa dos participantes. Explicou-se, inicialmente, que não era necessário identificar-se, que não existiam respostas certas ou erradas e que os dados seriam tratados com sigilo. Em seguida, justificou-se a presença do gravador e o propósito da sua utilização. Antes de iniciar a entrevista ou grupo focal, efetuava-se uma conversa sobre o ambiente rural, a fim de estabelecer um clima favorável para a realização da coleta de dados. Da mesma forma procedeu-se para a coleta de dados referentes aos agentes de desenvolvimento agrário, mudando apenas o local, que foi na Universidade Federal da Paraíba, em uma sala apropriada.

\section{Análise dos dados}

Os dados foram analisados a partir do conteúdo do discurso dos participantes, estabelecendo-se as unidades de análise que correspondiam às perguntas.

\section{Resultados}

Os resultados são apresentados de forma discursiva, em função das duas técnicas empregadas para a coleta de dados. A primeira técnica consistiu de entrevistas com os grupos focais, enquanto a segunda foi realizada através de entrevistas individuais. As entrevistas individuais foram utilizadas por causa da distância entre as residências dos assentados e dos moradores, o que impossibilitava reunir as pessoas em grupos para a realização da técnica de grupo focal. Em virtude da natureza qualitativa dessas técnicas, preferiu-se analisar os dois conjuntos de resultados de forma associada, ao invés de separadamente.

\section{a) Os assentados}

O assentamento estudado foi formado há seis anos (existe desde 1996) e constitui-se de 104 famílias. Está organizado em forma de parcelas, que correspondem à localização da casa do assentado dentro do seu lote de terra, e não sob a forma de agrovila, que o INCRA mais incentiva, em que a casa do assentado fica locada numa vila afastada de sua parcela de terra individual.

Quanto à proposta do INCRA, de organizar o assentamento em forma de agrovila, os assentados se manifestaram contra, alegando principalmente que o INCRA favorece este tipo de organização por facilitar e baratear a implementação do fornecimento de água e energia. Expressaram sua posição da seguinte maneira: "negócio de agrovila só é mais fácil para o governo, entendeu, porque coloca energia mais fácil, coloca água mais fácil, somente é mais vantagem para o governo, mas benefício para o agricultor, não tem não”.

Além disso, os assentados acreditam que, com a organização em forma de agrovila, suas casas ficam muito distantes da área de criação e plantio, possibilitando o furto de seus pertences e produção, devido à falta de vigilância constante. Isto pode ser exemplificado por expressões do tipo: “a gente viu que fica complicado a gente morar em agrovila e deixar as parcelas distantes de casa”; "imagine o cara que mora na agrovila que fica distante do roçado (...) pode ser até o vizinho mesmo, que tem deles que se escoram, que vai na plantação de milho e quebra, e o cabra não sabe quem foi”.

Os assentados acreditam que a agrovila é semelhante a uma favela, devido ao aglomerado de casas, e, por conseguinte, favorece o surgimento de problemas de relações interpessoais, como fofocas e brigas de vizinhos, entre outros: "Não dá certo porque tem o bom vizinho, também tem o mal vizinho, um cabra tem, uma comparação, uma ou duas, três crianças, numa agrovila e dá confusão, tem a mulher e sabe como a mulher é, quando dá fé tá aquele barulho e termina em briga”.

Quanto às expectativas com relação ao futuro do assentamento, verifica-se que os assentados esperam gerar emprego para seus filhos e que os mesmos continuem morando e trabalhando no assentamento. Este é um ponto forte no discurso dos participantes, que se destaca nos seguintes depoimentos: "espero do assentamento é que gere emprego para os nossos filhos não saírem para a cidade, que na cidade não existe emprego, que eles possam estudar, mexer mesmo com a terra e gerar emprego dentro do assentamento e trabalhar na terra”; “queremos gerar empregos, acho que é um sonho de cada parceleiro (assentado), acho que é gerar emprego para nossos próprios filhos e também para aqueles que precisam”.

Os assentados apresentaram também, como expectativa para o futuro do assentamento, o desejo de ter acesso à educação, lazer e saúde no próprio assentamento, quando afirmam, por exemplo, que "nosso sonho ainda é que aqui tenha um posto médico no assentamento, uma escola, um lazer no próprio assentamento".

Em relação aos pequenos proprietários, seus vizinhos, que residem em torno do assentamento, os assentados acreditam que eles são preconceituosos, por utilizarem adjetivos depreciativos para representá-los, como violentos, ladrões de terra e baderneiros. Além disso, os assentados consideram seus vizinhos como sendo invejosos, desorganizados, acomodados e medrosos. Pode-se supor que a relação entre estes dois grupos apresenta pouca integração e empatia. Percebe-se tal fato no discurso dos assentados com relação aos seus vizinhos: "acho que eles são invejosos, não têm coragem de lutar por um pedaço de terra como a gente lutou, ai 
fica dizendo que a gente tem animais, eletrodomésticos e outras coisas mais, que a gente tem é dinheiro do governo, são uns invejosos".

No tocante às crenças sobre o PRONAF, os assentados acreditam que o crédito implementado por este programa dificulta o pagamento, devido às altas taxas de juros (4\% a.a.). Da mesma forma, consideram o parcelamento do crédito como mais uma dificuldade para a sua utilização. Tomem-se, como exemplos, os seguintes relatos: "essa forma de programa (...) prejudica mais o pequeno agricultor”; “pra mim é mesma coisa, o que ele quer (governo) é complicar o pequeno agricultor".

Segundo os assentados, o trabalho dos agentes de desenvolvimento agrário é essencialmente de assistência técnica, no que diz respeito à forma tanto de plantar como de criar animais: "Um técnico aqui no assentamento facilita muito a vida da gente, eles dão vacinas nos animais e nos ensina”; "tem muita gente aqui que já está cuidando das plantas, sabe como produzir”. No entanto, os assentados crêem que o número de técnicos é insuficiente: “Os técnicos têm força de vontade para trabalhar e desenvolver, mas a demanda é grande, no meu pensamento deveria ser assim, cada assentamento deveria ter um técnico, por exemplo, e um assentamento acima de 80 famílias, dois técnicos, para ficar todo o dia ali, aí as coisas melhoravam”. Da mesma forma, os assentados se queixam da morosidade da liberação do fomento, mesmo atribuindo a responsabilidade ao INCRA e não propriamente aos técnicos. Estas crenças são identificadas quando os assentados dizem: "Eu tô querendo plantar milho, mas não tem dinheiro e eu tô esperando, já podia tá plantando esta semana, mas tem que esperar"; "porque o técnico trabalha assim dentro de uma norma, aí ele tem que dar o laudo, fazer a vistoria pra saber se tá no tempo (...) isso é uma lei que vem do Banco do Nordeste, aí ele fica com as mãos amarradas”. Notese que, mesmo estando insatisfeito com a atuação dos técnicos, no que diz respeito à liberação do fomento, os assentados atribuem a morosidade à burocracia do Banco do Nordeste e não à falta de competência dos técnicos.

\section{b) Agentes de desenvolvimento rural}

Quanto aos agentes de desenvolvimento agrário do INCRA (Lumiar), acreditam que o seu trabalho é fundamentalmente de fornecer assistência técnica, voltada para a orientação de como plantar e criar, bem como da melhor maneira de formar as cooperativas e associações. Não obstante, os técnicos consideram a sua atuação além dos objetivos estabelecidos pelo INCRA, mesmo considerando a insuficiência dos recursos humanos e materiais. Podem-se verificar estas crenças quando afirmam que: "Muitas vezes nós vamos muito mais além do INCRA (...) a gente faz assim, ou veste a camisa do assentado, ou veste a camisa do INCRA”.

Os técnicos acreditam que, no período anterior ao assentamento, os assentados lutam pela terra e são mais unidos, pois todos os indivíduos lutam por um mesmo objetivo, de modo que o interesse do grupo sobrepuja os interesses individuais. Outro aspecto suscitado pelos técnicos, é que boa parte dos assentados são citadinos e se iniciam na atividade agrícola no assentamento. Pode-se verificar tal fato quando os técnicos relatam que: “(...) então, a diferença do assentado que recebe a terra, recebe sem estrutura, sem recurso nenhum... Vai começar do zero”; "aqueles que de algum modo já residiam na terra, já começam de algo seu, de uma pequena base que pode fazer a diferença no futuro”.

De maneira semelhante aos assentados, os técnicos acreditam que a organização do assentamento em forma de agrovila apresenta alguns impasses para o seu bom funcionamento, como a distância da área de plantio e de criação da agrovila, a semelhança da agrovila com uma favela, e o ócio gerado devido à acomodação dos assentados, que se mantêm na agrovila ao invés de estarem desenvolvendo suas atividades laborais. Isto pode ser percebido quando afirmam: "É um pessoal que fica jogando dominó, ficam batendo papo, mas se tivessem um terreno (casa) no lote deles, eles tinham o que fazer".

\section{Discussão}

De acordo com os resultados, pode-se inferir que os assentados e os técnicos convergem na avaliação que fazem da organização do assentamento em forma de agrovila. Eles acreditam que este tipo de organização traz problemas para o assentado e para o assentamento como um todo, devido à localização da casa ser distante da área de plantio e de criação. A conseqüência é a diminuição da produção, em decorrência da perda de tempo com a locomoção do assentado, de sua casa para a área de plantio. Isto se deve, fundamentalmente, à precariedade dos meios de transporte neste ambiente, pois a agrovila pode distar três quilômetros ou mais do seu lote de terra. Além da iminente possibilidade de furto dos pertences, do plantio e da criação, por parte de assentados ou não-assentados, esse tipo de organização favorece o ócio dos assentados e de seus familiares, aumentando a freqüência de desentendimento entre eles, o que põe em risco as relações interpessoais no assentamento e o seu bom funcionamento. De fato, um bom relacionamento entre os assentados é de fundamental importância para que se possa implementar associações e cooperativas, aumentando assim a produção e os benefícios para o assentamento.

Para o INCRA e também para os movimentos sociais, por distintas razões, é mais vantajoso implementar e incentivar a formação de assentamentos em forma de agrovila, haja vista a diminuição dos custos com o fornecimento de água e energia, e a necessidade de manter os assentados unidos. Entretanto, não é pelo simples fato de estarem juntos que essa união se dará, mas será a necessidade determinada pelas condições de trabalho e produção, além do estabelecimento de metas. Tais metas, como, por exemplo, a criação de uma agroindústria, a melhoria das escolas e o estabelecimento de postos de saúde, precisam ser encarados como objetivos comuns, que necessitam do empenho de todos, para que sejam alcançados. Aqui se encontra um terreno fértil para o uso da psicologia social, tanto para entender os fenômenos 
que ocorrem, como para gerar intervenções que possibilitem uma melhor organização e compartilhamento de metas entre os assentados e, se for o caso, entre eles e os seus vizinhos.

Os experimentos de competição e cooperação, realizados por Sherif (1966, citado por Myers, 2000), são exemplos de como o estabelecimento de normas comuns a grupos ou a indivíduos de um determinado grupo ajuda a manter a união entre seus membros. Em um destes estudos, Sherif dividiu um grupo de 22 meninos em dois sub-grupos, em um acampamento de escoteiros, e fomentando a cooperação em cada sub-grupo, através de várias atividades como preparo das refeições e arrumação do acampamento, os meninos de cada sub-grupo tornaram-se unidos, estabelecendo uma identidade de grupo. Porém, quando se estabeleceram atividades competitivas entre os dois grupos, criou-se o conflito, evidenciado durante as atividades competitivas com atos como gritos, saques de cabanas e até agressões físicas. Assim, a coesão intragrupo é acentuada devido à existência de outro grupo, o que torna os integrantes de cada grupo mais cordiais uns com os outros, cooperativos e menos propensos à discussão, pois a ameaça é externa, o que resulta um maior sentimento de espírito de grupo.

Além da ameaça externa, outro aspecto salientado por Sherif é o poder unificador dos objetivos superiores, que exigem um esforço cooperativo (Myers, 2000). Ao estabelecer um objetivo superior (comum), Sherif fez com que os grupos que antes, em atividades competitivas, eram inimigos, passassem a uma situação de união. As atividades propostas só poderiam ser realizadas se os dois grupos cooperassem, o que promoveu a união entre os grupos e o fim da hostilidade por parte dos seus membros.

Em resumo, diz Myers (2000), “cada grupo primeiro se empenhou sozinho em atividades, depois competiu com o outro grupo, e depois cooperou com o outro grupo para alcançar objetivos superiores”, comum aos dois grupos (p. 294). Posteriormente, os estudos realizados por Blake e Mouton (1979, citados por Myers, 2000) evidenciaram, de forma inequívoca, que as relações entre adultos são equivalentes às reações encontradas entre os meninos estudados por Sherif.

Este é um exemplo de como se aplica a psicologia social, criando situações que modificam a estrutura de relações entre grupos e entre os membros de um mesmo grupo. Portanto, a criação de objetivos comuns, de atividades determinadas pelas condições de trabalho e produção, que necessitem da cooperação, são exemplos de metodologias e ações que podem auxiliar na manutenção do bom funcionamento de um assentamento e na manutenção da união entre os assentados.

No que se refere às suas expectativas, os assentados esperam não só gerar possibilidades de trabalho para seus filhos (assentados) e terceiros (não-assentados), como também se manter na terra, para que seus filhos tenham um futuro assegurado no assentamento. Nesse sentido, a educação se apresenta como um aspecto importante para os assentados, pois eles consideram a sua formação escolar como fundamental para a garantia de um futuro melhor. Este é um exemplo do que poderia ser enfatizado pelos órgãos que assistem os assentamentos, no sentido de gerar condições para que se estabeleçam laços entre os assentados e não-assentados, através de projetos comuns, como a construção de escolas e a participação em cursos profissionalizantes, entre outros. É necessário que se tenha uma visão clara dessas condições, para que, se possa encontrar maneiras de viabilizá-las.

No tocante às relações com as comunidades vizinhas, percebe-se um isolamento entre os assentados e a circunvizinhança. A falta de entendimento entre estes dois grupos é evidenciada quando os assentados ressaltam que seus vizinhos têm uma percepção estereotipada sobre eles, considerando-os violentos, ladrões de terra e baderneiros. Assim, verifica-se pouca relação entre eles, mostrando que o objetivo de integrar os assentados e as comunidades vizinhas não tem sido alcançado. Provavelmente, a compreensão das políticas públicas separadas entre assentados e pequenos proprietários fortalece esta divisão, na medida em que objetivos comuns não são estabelecidos para que eles possam desenvolver metas e relações que facilitem a sua integração. Neste aspecto, os trabalhos sobre cooperação e competição, estudados pela psicologia social, podem ser de grande utilidade para o planejamento de ações estratégicas no processo de reforma agrária. A principal dessas ações salienta a impossibilidade de gerar essa integração sem considerar, no planejamento das políticas públicas, toda a região, e não apenas os assentados.

O Programa Nacional de Fortalecimento da Agricultura Familiar (PRONAF), que poderia ser utilizado como instrumento de facilitação para a integração entre assentados e seus vizinhos, pois se trata de uma linha de crédito aberta a todos os pequenos agricultores, mantém-se, apenas, como um crédito individual a mais. Esta visão instrumental de conjunto necessita ser melhor discutida no âmbito do Ministério Extraordinário de Política Fundiária, junto ao INCRA e seus técnicos. Isto ajudará a modificar a visão particularista que permeia o trabalho voltado para os assentamentos, desprezando a regionalização da assistência técnica e de ações que poderiam ser mais abrangentes e favorecendo uma integração mais rápida dos assentados com as comunidades vizinhas. Sobre o crédito agrícola oriundo do PRONAF, assentados e técnicos compartilham a visão particularista, reclamando apenas de aspectos funcionais, como o parcelamento do crédito e dos juros altos. Em resumo, os assentados acreditam que o PRONAF traz poucos benefícios para a sua categoria, porém não avançam na compreensão de propor um tipo de crédito diferenciado, que englobe todos, inclusive a circunvizinhança.

Quanto ao trabalho dos agentes de desenvolvimento agrário, os assentados apresentam crenças positivas em relação à sua atuação no assentamento, ressaltando o auxílio dado no momento do plantio e a orientação sobre a criação, isto é, acreditam que os técnicos realizam um trabalho importante para o desenvolvimento da produção. No entanto, algumas crenças negativas são apresentadas, não necessariamente direcionadas para os técnicos, mas para o órgão no qual prestam serviço: (1) a quantidade de técnicos não é suficiente para atender à demanda dos assentamentos, diminuindo assim a freqüência das visitas; (2) a liberação de fomento é dificultada pelo INCRA e é previamente direcionada para 
projetos de plantio, sem levar em consideração as condições de fertilidade da terra, pois o assentamento estudado apresenta uma terra pouco fértil e facilmente erodida. Entretanto, alguns assentados, mesmo contrariando as regras do INCRA, conseguem aproveitar o seu fomento para criar galinhas, porcos, bodes e vacas. Dessa maneira, apresentam melhores condições financeiras do que os que estão unicamente voltados para o plantio, como o INCRA espera que seja utilizado o fomento. Em suma, é sabido pelos assentados que os técnicos têm dificuldades de desenvolver os seus trabalhos, devido às limitações impostas pelo INCRA. Mesmo assim, com todos os impasses institucionais, os assentados crêem que a assistência dada pelos técnicos é de fundamental importância para o desenvolvimento do assentamento e o seu bom funcionamento. Torna-se difícil compreender as razões que levaram o INCRA a suspender este projeto de assistência técnica, sem substituí-lo por outro. Nas condições em que se encontram os assentados, sem instrução, com terras improdutivas e sem assistência técnica especializada, por mais crédito que consigam (e conseguem pouco) dificilmente atingirão suas metas de autodesenvolvimento. Pode-se vislumbrar aí um dos prováveis pontos de estrangulamento da produção e o fortalecimento da dependência dos assentados em relação ao Estado.

Pode-se supor, também, que os técnicos acreditam que o seu papel é de prestar assistência à produção, visando a melhoria da organização do assentamento, no que diz respeito à sua estruturação social, bem como à maximização da produção agropecuária. Outrossim, acreditam que, na sua atuação, perpassam os objetivos impostos pelo INCRA, mesmo com as limitações humanas e materiais. Parece haver um descompasso entre o papel que os técnicos julgam desempenhar e aquele que a instituição, ou os seus representantes, determinam que sejam cumpridos. Provavelmente, o pano de fundo dessa discrepância se encontra no discurso ideológico de cada um dos agentes.

No que se refere ao financiamento direcionado aos assentados, os técnicos acreditam que este fomento não atende às necessidades do grupo, pois a forma de pagamento dificulta a quitação das dívidas. Segundo eles, as taxas de juros de $4 \%$ ao ano são muito altas para a agricultura praticada. Os técnicos ressaltam que o fomento é insuficiente para atender as necessidades surgidas entre o momento do plantio e o momento da colheita, pois é no período intermediário que está a fase crítica, quando os assentados não têm como manter sua subsistência.

Uma alternativa para esta dificuldade seria a implementação de um crédito de manutenção das famílias, vinculado a investimentos a longo prazo em frutíferas ou lenhosas, que são árvores com baixo custo de implantação, mas com elevado valor agregado. Estes investimentos poderiam, em um prazo entre cinco e dez anos, propiciar condições para resgatar a dívida contraída pelos agricultores e seus familiares. Este tipo de crédito dar-se-ia através de remunerações mensais às famílias dos agricultores, com um valor aproximado ao do salário mínimo, como forma de manter a família viva, enquanto o projeto se desenvolve ao longo do tempo.
Por fim, assentados e técnicos crêem que o Estado é responsável por dar as condições necessárias para o bom funcionamento do assentamento, a partir da desapropriação das terras, até o plantio e a criação. Eles acreditam que o assentamento é um projeto viável de reforma agrária, mas que, para dar certo, necessita de mais apoio financeiro do Estado.

\section{Conclusões}

Embora os projetos de assentamento tenham por finalidade integrar os assentados às comunidades vizinhas e proporcionar que eles possam produzir para a sua subsistência e comercialização, estes objetivos não têm sido alcançados. $\mathrm{O}$ INCRA e o Movimento dos Trabalhadores Rurais Sem Terra parecem não perceber tais finalidades, isolando os assentamentos de sua circunvizinhança. As políticas públicas implementadas nestes projetos e os esforços dos técnicos do Projeto Lumiar têm sido onerosos para os cofres públicos e obtido pouco retorno. Como exemplo, pode-se citar o assentamento estudado, no qual, após seis anos de existência, as pessoas assentadas ainda não deixaram de se diferenciar economicamente dos seus vizinhos, bem como não apresentam condições de produzir sem o apoio do Estado, seja para a sua subsistência, seja para a comercialização. Pode-se supor que este último objetivo não foi alcançado devido à péssima qualidade da terra onde estas pessoas foram assentadas. A terra se caracteriza como improdutiva, neste caso, devido à falta de adequação para a atividade agrária.

Essa questão da desapropriação das terras merece um maior cuidado, porque ela não deve ser considerada de forma homogênea, mas sim de vários ângulos, uma vez que os diversos atores nela envolvidos representam papéis e interesses distintos. Do ponto de vista dos movimentos sociais, geralmente a desapropriação é tida como uma estratégia na luta pela mudança das estruturas da sociedade. No outro extremo, encontram-se os proprietários de terras, que muitas vezes são os grandes beneficiados de todo esse processo, pois conseguem vender suas terras por valores, em alguns casos, muitas vezes superiores ao preço de mercado. Isso considerando que os processos correram de forma honesta e normal, o que nem sempre é verdade, segundo dados do próprio Ministério Extraordinário de Política Fundiária (2001).

Portanto, faz-se necessário muito mais empenho por parte do INCRA e do Movimento dos Trabalhadores Rurais Sem Terra (MST), para implementar uma reforma agrária eficaz, a começar no momento da escolha das terras a serem desapropriadas. É possível que a implementação do Banco da Terra, por possibilitar que os próprios agricultores escolham a terra a comprar, aponte uma saída para esse impasse. Mais uma vez, entretanto, faz-se necessário muito cuidado porque, quase sempre, são os proprietários de grandes extensões de terras que estão tomando a iniciativa de retalhálas, a bom preço, através dos órgãos responsáveis pela reforma agrária.

Outro aspecto a ser considerado é a forma de crédito ofertada aos assentados. O crédito pode ser um forte instru- 
mento de direcionamento dos assentados, para atingirem objetivos de desenvolvimento regional que vão além do aspecto meramente agrícola. Uma política de crédito para pequenos agricultores deveria contemplar tanto os assentados quanto os seus vizinhos, colocando-os em atividades comuns, como a estruturação de agroindústrias, além de conter uma parte de custeio determinada à manutenção da família do agricultor. Esta parte de custeio poderia estar vinculada a investimentos em frutíferas e lenhosas, que são de baixo custo de implementação e agregam elevado valor no decorrer dos anos.

É de extrema necessidade realizar mais estudos nesta área, para se propor metodologias e ações que contribuam para o melhoramento do processo de reforma agrária no Brasil, bem como para abandonar a idéia de uma agricultura patronal excludente da agricultura familiar. Isto tornaria o ambiente rural mais atraente, fazendo com que as pessoas possam nele permanecer, e seduzindo as que migraram para os centros urbanos, de forma que possam retornar tendo as condições necessárias para trabalhar e garantir uma melhor qualidade de vida.

\section{Agradecimento}

Os autores agradecem ao Professor Dr. Jorge da Silva Raymundo pela revisão e sugestões ao texto.

\section{Referências}

Albuquerque, F. J. B., Lobo, A. L., \& Raymundo, J. S. (1999). Análise das repercussões psicossociais decorrentes da concessão de benefícios rurais. Psicologia: Reflexão e Crítica, 12(2), 503-519.
Buanain, A. M., Silveira, J. M., \& Teófilo E. (1998). Reforma agrária, desenvolvimento e participação: uma discussão das transformações e necessidades possíveis. Retirado em 01 de fevereiro de 2001, do Núcleo de Estudos Agrários e Desenvolvimento, do World Wide Web: http://www.nead.gov.br/estudos.

Bittencourt, G. A., Castilho, D. S. B., Bianchini, V., \& Silva, H. B. C. (1999). Principais fatores que afetam o desenvolvimento dos assentamentos de reforma agrária no Brasil. Brasília: Coordenação de Comunicação Social do Ministério do Desenvolvimento Agrário.

Carmo, R. B. A. (1999). A questão agrária e o perfil da agricultura familiar brasileira. Retirado em 03 de maio de 2001, do World Wide Web: http:// www.bahia.ba.gov.br/seagri/revbagr/rer_112000/questaoagraria.htm. http:/ /www.cria.org.br/gip/gipaf/itens/pub/sober

Carneiro, M. J. (1998). Política pública e agricultura familiar: uma leitura do PRONAF. Retirado em 07 de fevereiro de 2001, do Departamento de Estudos Sócio-econômico Rurais, do World Wide Web: http://www.deser.org.br/ publicacoes.htmhttp://www.cria.org.br/gip/gipaf/itens/publ/deser/deser97.rtf.

Carvalho, H. M. (1998). Formas de associativismo vivenciadas pelos trabalhadores rurais nas áreas oficiais de reforma agrária no Brasil. Retirado em 05 de abril de 2001, do dataterra, do World Wide Web: http:// www.dataterra.org.br/documentos/horacio3.htm.

Leite, S. (1998). Assentamentos rurais: um balanço da experiência brasileira. Retirado em 03 de abril de 2001, do dataterra, do World Wide Web: http:/ /www.dataterra.org.br/seminario/serlei.htm.

Ministério Extraordinário de Política Fundiária (2001). Reforma agrária e desenvolvimento da agricultura familiar como vetor estratégico do desenvolvimento rural. Retirado em 02 de março de 2001, do World Wide Web: http://www.desenvolvimentoagrario.gov.br/espaco/pubs/pubs.htm.

Myers, D. G. (2000). Psicologia Social. Rio de Janeiro: LTC.

Rokeach, M. (1981). Crenças, atitudes e valores (A. M. M. Barbosa, Trad.). Rio de Janeiro: Interciência. (Texto original publicado em 1968)

Rodríguez, A., \& Ardid, M. (1996). Psicología Social y políticas públicas. In J. L. A. Estramiana, A. Garrido, \& J. R. Torregrosa (Orgs.), Psicología Social aplicada (pp. 451-474). Madrid: McGraw-Hill.

Teixeira, E. C., \& Martin, M. A. (1998). Retornos aos investimentos no setor não agrícola e agrícola da economia brasileira. Revista de Econometria, 2, 73-92.

Francisco José Batista de Albuquerque, doutor em Psicologia Social pela Universidad Complutense de Madrid (Espanha), é professor no departamento de Psicologia, Universidade Federal da Paraíba. Endereço para correspondência: Rua Maria Jaci Pinto da Costa, 201, bloco B, ap. 1101; João Pessoa, PB; CEP 58036110.E-mail: frajoba@uol.com.br

Jorge Artur Peçanha de Miranda Coelho é aluno do mestrado em Psicologia Social da Universidade Federal da Paraíba.

Tatiana Cristina Vasconcelos é aluna do mestrado em Psicologia Social da Universidade Federal da Paraíba. 